\title{
The impacts of Covid-19 on circular economy: Gaining insight across the SCOPUS and Web of Science research articles with Text Mining techniques.
}

\author{
Khoa Tran \\ New York University Abu Dhabi \\ khoa.tran@nyu.edu \\ https://orcid.org/0000-0001-8000-1027
}

\author{
Tuyet Anh Nguyen \\ Nguyen Chi Thanh Gifted High School \\ anhtuyetmoi@gmail.com \\ https://orcid.org/0000-0001-7308-3677
}

\begin{abstract}
The emergence of the Covid-19 pandemic has created both negative and positive changes, including implementing the circular economy across the globe. This Systematic Review follows the PRISMA statement and employs the Text Mining (Voyant Tools) technique to visualize and analyze the impacts of the Covid-19 on three aspects of the circular economy: economic, social, and environmental. The research employs Latent Dirichlet Allocation (LDA) to identify five major topics: (1) Shortage of medical equipment but high medical waste during Covid-19 due to the high demand in healthcare; (2) The long term negative impacts of lockdown on economic and social activities because of Covid-19 pandemic; (3) The reports on impacts of Covid-19 pandemic on the manufacturing globally, and their coping strategies and new opportunities; (4) The impacts of international restriction on the tourism, trade, shipping, and aviation industry, causing billiondollar losses; (5) The reduction of pollution with health environment improvements with example cases from China and EU. The research identifies current literature gaps in the circular economy
\end{abstract}


and Covid- 19 topics and encourages the application of text mining tools into researching to stimulate the research process and assist in communicating with the public.

Keywords: circular economy, Covid-19, Voyant tools, environmental sustainability, social sustainability, economic sustainability, text mining.

\section{Introduction:}

In 2015, world leaders had gathered together to initiate the 17 sustainable development goals 2030, which is the blueprint for world development concentrating around the keyword "sustainability." In this agenda, sustainability must fulfill three aspects: economic, social, and environmental. Circular economy, argumentatively, is the core economic model to achieve this global agenda. According to The Ellen Macarthur Foundation, a circular economy is a systemic economic development that encourages the reuse and recycling of resources within an economic system and gradually declines in consulting virgin resources from nature. This economic system has three principles: (1) Design out waste and pollution; (2) Keep products and materials in use; (3) Regenerate natural systems. Various research has supported a circular economy's benefits in promoting all economic sustainability, social sustainability, and environmental sustainability.

Regarding Economics, a circular economy ensures substantial resource savings and resource optimization (Agardy and Nemerow; Haggar 85-124), and positive employment growth from new jobs (Reilly); hence, it promotes economic growth. This model also promotes innovation from firms across the world to improve their product novelty and service quality (Pieroni et al.; Chen). Implementing circular economy concepts in business, such as reverse logistics, also increases profitability, variable costs reduction (Linder and Williander), and increases brand 
reputation for businesses (Murray et al.). According to the European Parliament, this economic model will save $€ 600$ billion for EU businesses and create 580,000 jobs by 2030 . Alone in the United Kingdom, business analytic confidence that a circular economy might generate 50,000 new jobs and $€ 12$ billion of investment. While in the Netherlands, the circular economy adds $€ 7.3$ billion/year to market values and creates 54,000 jobs (Kalmykova et al.). This model also benefits developing countries. For example, China is estimated to gain from 589 billion to 819 billion USD in GDP gains by 2030 by improved recycling practices. The reduction in demand for raw material in developed countries also helps most developing countries benefiting from lower raw materials, such as steel (Nechifor et al.). However, the benefits between developed and developing countries are not balanced without inclusive circular economy priorities and fair international trade management systems (Preston et al.).

Socially, a circular economy also brings stability and benefits for underprivileged citizens and minority groups, such as their double income in three years, new jobs for women across Burkina Faso, Ethiopia, Ghana, Kenya, Mauritius, South Africa, and Uganda (Atani). It also reduces unemployment in the United Kingdom, especially in the highest unemployment areas, and mitigates regional unemployment disparities (Morgan and Mitchell). According to the European Commission's technical report, the circular economy promotes equal distribution of income across EU citizens if resource productivity increases $2 \%$ in the EU. According to the World Health Organization (WHO) report, higher employment has positive psychological and physical health benefits because higher employment in society allows citizens to consume healthier food. Various research also indicates the benefit of product responsibility, social inclusion, fair distribution of income, and many other benefits; however, scholars critique these benefits as lacking quantitative 
evidence and the least conceptualized framework among three aspects (Padilla-Rivera et al.; Sehnem et al.; Murray et al.).

Environmentally, the circular economy's benefits are well supported and significant. The benefits include but are not limited to raw materials reduction, energy reduction, waste reduction, and many other benefits (Sehnem et al.). Based on economic modeling, Ellen MacArthur Foundation and McKinsey Center for Business and Environment researchers believe that GHG emissions will decline up to $48 \%$ by 2030 and up to $83 \%$ by 2050 if the world implements circular economy principles in business and policies (Rizos et al.). Moreover, the circular economy in the progressive scenario can cut up to $296 / 530$ million tons CO2/year in the EU and 3.6 billion tonnes/year worldwide by 2050; these benefits ensure global citizens' health safety (Enkvist and Klevnäs). The circular economy also protects diversity worldwide. For example, eutrophication results in the water body's oxygen depletion due to excessive growth of algae after feeding phosphorus waste. This problem causes marine creatures to die. Hence with the circular economy, the reduction in phosphorus usage, and improvement in phosphorus recycling, the incidents of eutrophication reduce (Smits and Woltjer).

\section{The impacts of Covid-19 on the Economy.}

On the 11th March 2020, the WHO officially announced the Covid-19 outbreak as a global pandemic. Although governments worldwide have stringently introduced sweeping changes such as imposing national lockdowns and sealing their borders to contain the novel coronavirus's spread, its repercussions on economic activities are irreversibly substantial. According to the World Tourism Organization (UNWTO) until August 2020, the fall in international arrivals translates into a loss of US\$ 730 billion in export revenues from international tourism, more than eight times 
the loss experienced after the 2009 global financial crisis. According to the World Trade Organization, Covid-19 might also trigger a 9.2\% drop in the volume of world merchandise trade for 2020. Along with massive job loss and deepened income inequality, an estimated 49 million people will suffer from extreme poverty, and the world is likely to experience the first increase in global poverty since 1998 (Mahler et al.,). In its October 2020, the International Monetary Fund (IMF) forecast a colossal economic loss with global growth projected at -4.4 percent in 2020 .

However, some drastic changes that positively impact human life also occur during the Covid-19 pandemic. The population confinement leads the transportation sector to halt and industrial and manufacturing activities to drop, paying the way for the reduction of emission from fuel combustion, hence the plunge in natural resource usage and the temporary improvement of air quality (Le Quéré et al.; Muhammad et al.). While excessive environmental noise can lead to health-related problems such as impairment in children's cognitive development, sleep disturbance, and cardiovascular diseases, people's physical and mental health can be improved thanks to a significant plummet in noise pollution attributable to the decline of both road and air traffic movements (Fritschi). As communities are together involved in combating the pandemic, social cohesion or social conscience are leveraged, and people utilize the opportunity of studying and working remotely from home to bond with family members.

Due to the bipolar nature of Covid-19 impacts on the circular economy development, there are three questions we want to address with this systematic review:

1. Summarizing the overall research trends about the impacts of Covid-19 on the circular economy development across the world. 
2. Finding the most prominent challenges in each aspect of the circular economy (Economy, Social, Environment) that have been pointed out and addressed by researchers in the Scopus and WOS database?

3. Suggesting directions for future research and studies on aspects of the circular economy during and after the Covid-19 pandemic.

Since Scopus and Web of Science (WOS) are two leading international scientific bases whose content are meticulously curated and ultimately published (Chadegani et al.), this paper aggregates articles on Covid-19 and circular economy from Scopus and WOS journals, which are published from early 2020 onward, to analyze insights and trends for the post-Covid-19 world.

\section{Voyant Tools for qualitative researchers and visualizations:}

To answer the question on the impacts of Covid-19 on circular economy development, we want to employ text mining on all research about circular economy and Covid-19 from Scopus and the World of Science database. Quantitative analysis of qualitative data is a new application in other social sciences and humanities. This is because the distant reading and quantification of texts might isolate words out of context and disconnect the words with their contextualized meaning (Hetenyi et al.). However, quantitative analysis of qualitative data has become more mathematically developed and applied to various social science and humanity research, resulting in a new research technique called: text mining. Text mining allows researchers to find patterns and trends in "unstructured data" from textual information based on statistics, machine learning, and linguistics algorithms. Text mining's major benefits are processing large textual data to extract "high quality" information and providing insights into the specific scenario (Talabis et al. 1-12). The application of this technique is seen in research across cybersecurity, biomedical literature analysis, online 
media analysis, anthropology, disease classification, and analytical customer relationship management (Han et al.; Peng et al.; Nettleton 171-179; Marwick).

Voyant Tools is an open-source, web-based application for performing text analysis with the integration of tools, such as Latent Dirichlet allocation (LDA), t-Distributed Stochastic Neighbour Embedding, allowing flexibility in textual data analysis and visualization. 35 scholarly research pieces in the Scopus database have employed Voyant Tools to extract insightful information from mass textual data across disciplines. For example, Nukhu and Singh employed linked analysis and word trees from Voyant tools to find the city image's core attributes and focus group interview and review text scrapped from TripAdvisor in urban development and tourism research (Nukhu and Singh). Scholars also use this tool to find constructions and elements of an abstract word from expert interviews and research publications. Neave uses Voyant Tools to analyze published interviews with fiction writers and biomedical scientists, finding the constructions of "discovery" from scientific and literature perspectives. Finally, Voyant tools can also detect trends and interests in discipline across multiple periods of time (Gao). This research uses these techniques to spot the development trends in circular economy research during the Covid-19 pandemic and generate insightful data from them. 


\section{Methodology:}

\section{Preferred Reporting Items for Systematic Reviews and Meta- Analyses (PRISMA)}

PRISMA Statement is a method of literature review developed by Cochrane authors. It aims to help researchers improve their analysis of systematic reviews and meta-analyses, ensuring a standard guideline for systematic reviews. This process has four stages (See Figure 1): identification, screening, eligibility, and then qualitative analysis of included articles (Moher et al.)

To gather relevant research on Covid-19 and circular economy, we employ keywords “circular economy," “CoronaVirus," “Covid-19”. The Inclusion Criteria (IC) for articles chosen: (IC1) peer-reviewed research; (IC2) explicit mention of the relationships between Covid-19 and circular economy; (IC3) written in English. The Exclusion Criteria are (EC1) articles not written in English; (EC2) articles without an author; (EC3) articles without available DOI or Url on SCOPUS or WOS database. The results after PRISMA's four stages are: 


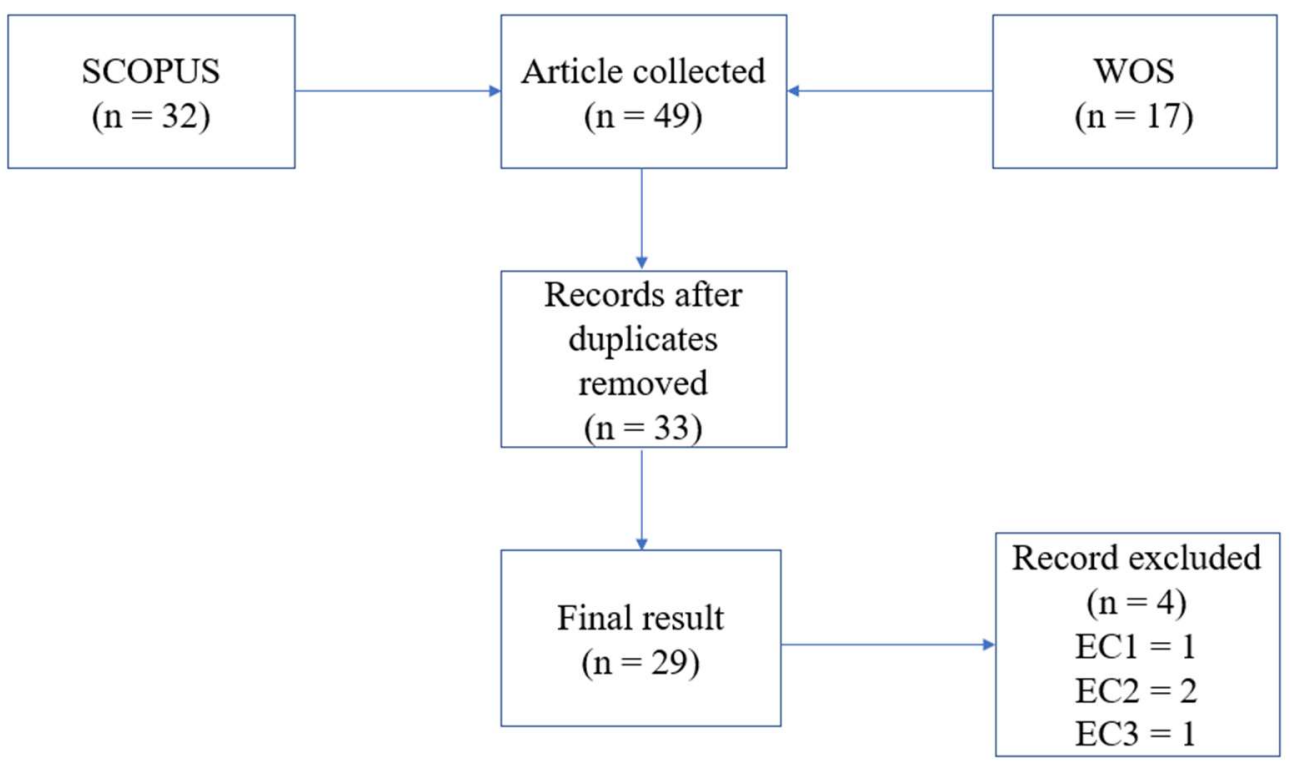

Figure 1. The phases that make up the systematic review, adopting from (Moher et al.)

To further analyze the impacts of Covid-19 on individual aspects of the circular economy, we also categorize the 29 articles gathered into 4 folders: Environment, Economic, Social, and All articles (see Figure 2). Some articles touch on multiple aspects of circular economy; hence, they appear in more than one folder. We categorize based on close reading along with keywords visualization from Voyant Tools. 


\begin{tabular}{|l|l|}
\hline Article Themes & Number of Articles \\
\hline Economic Aspect & 21 Articles \\
\hline Social Aspect & 17 Articles \\
\hline Environmental Aspect & 13 Articles \\
\hline Total numbers of articles & 29 Articles \\
\hline
\end{tabular}

Figure 2: The number of articles per aspect of the circular economy taken from SCOPUS and WoS databases.

\section{Data-mining with Voyant Tools}

To analyze and visualize the textual data from collected articles, we used 5 analytical tools from Voyant Tools: Cyrrus Tool, Linked Analysis, Correlation Tool, Topics Tool, and Trend. These tools have been used in the research across disciplines and will help to visualize the insights from the research questions and guide our close reading analysis:

1. Summarizing the overall research trends about the impacts of Covid-19 on the circular economy development across the world.

2. Finding the most prominent challenges in each aspect of the circular economy (Economy, Social, Environment) that have been pointed out and addressed by researchers in the Scopus and WOS database? 
3. Suggesting directions for future research and studies on aspects of the circular economy during and after the Covid-19 pandemic.

Cirrus Tool creates a word cloud that visualizes the top frequency words of a corpus or document. All the stopping words, such as "the", "a", "and",... will be removed in the process. Scholars have used the application of the Cirrus Tool (word cloud) in sustainability research and business. For example, researchers use word clouds to (1) find the most important keywords in building smart cities, (2) identify major elements of hierarchical, egalitarian, or individualistic discourse in energy transition in Austrian climate, (3) analyze city branding, and (4) conduct marketing interview analysis. Employing this tool, we can find out the significant and highly mentioned keywords across the research on the impacts of Covid-19 on the circular economy.

Linked Analysis utilizes force directed graphs to visualize natural and aesthetically pleasing ways. Although this technique is based solely on the information contained in text rather than relying on domain-specific knowledge, Linked Analysis still gives insight into the impacts of Covid-19 on the circular economy based on the collocations of keywords across different articles. The larger size of the word in this graph represents the higher frequency it appears in all research articles.

Correlation Tool employs Pearson correlation calculations to calculate the correlation between two words. The tool also provides the significance level for each pair of words. Corpus Collocates is a table view of which terms appear more frequently in proximity to keywords across the entire corpus. With the Correlation Tool and Corpus Collocates, we can analyze the inter-relationship between the 3 keywords "Economic," "Social" and "Environment" to see whether researchers tend to incorporate multi-dimensional Analysis for their research or investigate each aspect of the 
circular economy solely. We can also employ this tool to find sub-research topics under a given theme, such as "what are the most researched topics in the healthcare sector?"

Topics Tool employs Latent Dirichlet Allocation (LDA), a statistical model for abstract topics discovery and topics modeling. LDA assumes that phrases and words in the text belong to latent topics and categorize them together. LDA can discover (1) the hidden themes in a collection of words and (2) classify the articles into the discovered themes. To cluster text collections, LDA utilizes a probabilistic model that adheres to the fact that authors tend to rewrite similar words when discussing the same topic. Therefore, LDL uses the cooccurrences of words to illustrate each topic as a probability distribution over words and each document as a probability distribution over topics (Schwarz). Increasing the iteration can narrow down the topics and increase mathematical reliability in predicting themes. Topic Tool then samples new topic assignments for texts in the collections. Previous research has used this technique for online public opinion analysis (Zhou et al.), tourist reviews analysis (Kirilenko et al.), and building AI for the content recommendations (Singh et al. 1-10). This tool can generalize hidden trends in all research articles about the impacts of Covid-19 on the circular economy.

Trends is a visualization method that represents the frequencies of terms across documents in a corpus. This tool allows researchers to identify the keyword trend across each month and each aspect of the circular economy during Covid-19. The application of Trends for this purpose has been used by various researchers since 2018 (Gao). 


\section{Data Analysis and Results Presentation}

In this session, we will go through all the essential text-mining visualization taken from the comprehensive corpus with 29 articles. This session concentrates on insight analysis without closereading and in-depth theoretical discussion. The discussions will be concentrated on discussion sessions.

Figure 3: The word cloud illustrations of the whole corpus of the impacts of Covid-19 on the circular economy.

According to Figure 3 and after taking out 3 topic words "economy," "circular," and "Covid," the highest words frequency are: waste (rank 1), food (rank 2), supply (rank 3), production (rank 4), and management (rank 5). In contrast, keywords related to government, such as European (rank 25), policy (rank 31), government (rank 78), are ranked less significantly. The 
trend illustrates the concentration of research on microeconomic management rather than macroeconomic, governmental actions and policies during the Covid-19 pandemic.

From the word cloud visualization (Figure 3) and close reading, the most research industries are summerized in Figure 4: Environment and Waste Management Industry (Rank 1), Food industry and Beverage (Rank 2), Healthcare industry (Rank 3), Supply Chain (Rank 4), Energy Industry (Rank 5), Water Industry (Rank 6), Services Industry (Rank 7), Agriculture Industry (Rank 8), and Tourism (Rank 9). This rank has accounted for keywords combination, such as healthcare includes keywords "medical," "dental," "pharmacy," or supply chain includes "transportation," "supply," "production," "resource management." All industries with less than 100-word counts will be excluded from analysis because of minimal research, such as the industry and education.

\begin{tabular}{|l|l|l|}
\hline Name of industries & Key research articles & Collocations \\
\hline Environment and & (Vanapalli et al.; & waste management, waste disposal, waste \\
Industry & Zaleski and Chawla; & collection, waste generation, waste smart, waste \\
Rada et al.; Chauhan & recycling, waste energy, waste processing, \\
Industry & $\begin{array}{l}\text { (Giudice et al.; Mohan } \\
\text { et al.) }\end{array}$ & $\begin{array}{l}\text { food waste, food systems, food production, food } \\
\text { supply, food security, food sustainability, food } \\
\text { Food and Beverage }\end{array}$ \\
& $\begin{array}{l}\text { (Mahler et al.; } \\
\text { Chauhan et al.) }\end{array}$ & $\begin{array}{l}\text { health waste, health disposal, healthcare system, } \\
\text { health management, health and food, dental, } \\
\text { healthcare services. }\end{array}$ \\
\end{tabular}




\begin{tabular}{|c|c|c|}
\hline $\begin{array}{l}\text { Supply } \\
\text { Industry }\end{array}$ & $\begin{array}{l}\text { (Sharmina et al.; } \\
\text { Rahman et al.; Nandi } \\
\text { et al.) }\end{array}$ & $\begin{array}{l}\text { supply chain localization, supply chain Covid- } \\
\text { 19, supply chain agility, supply chain resilience, } \\
\text { supply chain sustainability }\end{array}$ \\
\hline Energy Industry & $\begin{array}{l}\text { (Sharmina et al.; } \\
\text { Varbanov et al.) }\end{array}$ & $\begin{array}{l}\text { energy waste, energy storage, energy efficiency, } \\
\text { energy intensity, energy production, energy } \\
\text { heat, energy integration, energy and water }\end{array}$ \\
\hline Water Industry & $\begin{array}{l}\text { (Mohan et al.; } \\
\text { Varbanov et al.) }\end{array}$ & $\begin{array}{l}\text { water footprint, water pollution, water } \\
\text { resources, water scarcity, water energy, water } \\
\text { availability, water risk, water food }\end{array}$ \\
\hline Services Industry & (Patel) & $\begin{array}{l}\text { service utilization, service dental, service } \\
\text { products, service goods, service food, service } \\
\text { urban }\end{array}$ \\
\hline $\begin{array}{l}\text { Technology } \\
\text { Industry }\end{array}$ & $\begin{array}{l}\text { (Nandi et al.; Chauhan } \\
\text { et al.) }\end{array}$ & $\begin{array}{l}\text { technology university, technology transfer, } \\
\text { technology applied, technology research, } \\
\text { technology waste }\end{array}$ \\
\hline Agriculture Industry & $\begin{array}{l}\text { (Dewick et al.; Mohan } \\
\text { et al.; Barcaccia et al.; } \\
\text { Lal et al.) }\end{array}$ & $\begin{array}{l}\text { food, industry } 4.0 \text {, agriculture research, forestry, } \\
\text { agriculture sustainability, agriculture farming, } \\
\text { soil management }\end{array}$ \\
\hline Tourism Industry & $\begin{array}{l}\text { (Prideaux et } \\
\text { Ateljevic) }\end{array}$ & $\begin{array}{l}\text { Covid-19, local, global, transformative, } \\
\text { geographies, flow, recovery, geopolitics } \\
\text { cancellation, }\end{array}$ \\
\hline
\end{tabular}

Figure 4: The summary of key industries from the literature review, their key research, and their key themes based on Voyant Tools' trend and correlation tools. 


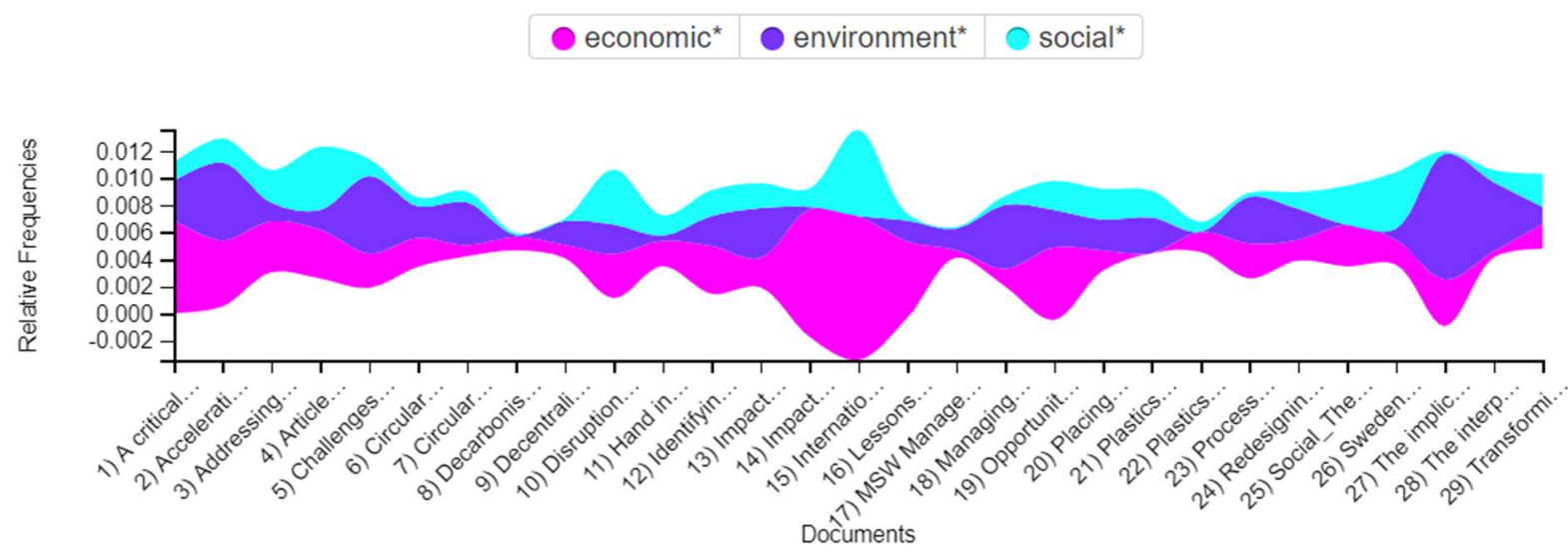

Figure 5: The collocation of economic, social, and environmental.

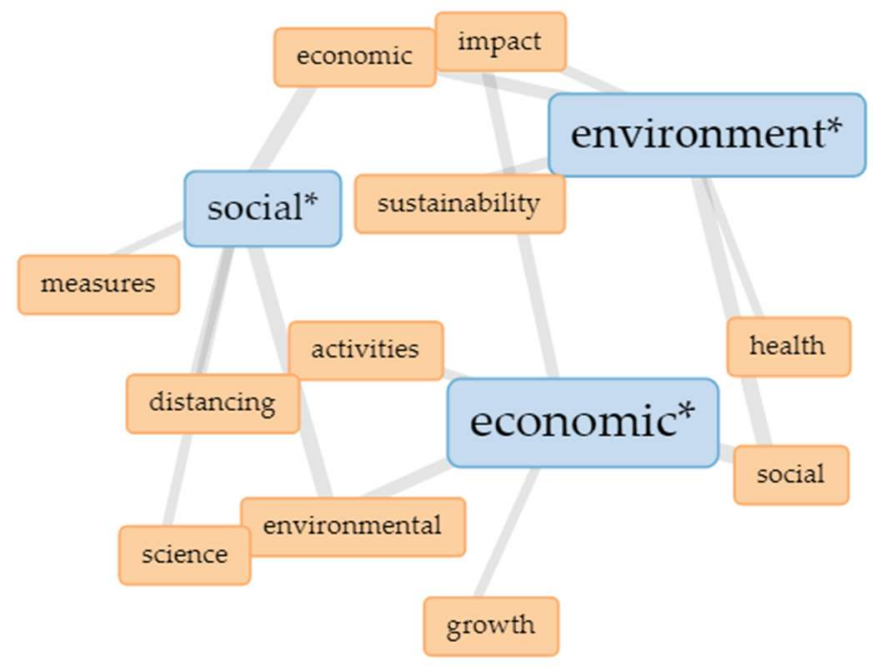

Figure 6: Visualization of Linked Analysis in each keyword "economics," "environment," and "social," automatically generated by Voyant Tools.

One fascinating insight is that all three aspects of the circular economy have the highest collocative frequency (Figure 5 and Figure 6). The collocation measures the frequency that two words occur together within all articles using Pearson correlation calculations; this illustration, as a whole picture, may suggest that all researchers are assessing three aspects as interconnectivity rather than investigating each aspect in isolation. The StreamGraph also highlights that nearly all 
29 articles address all three aspects of the circular economy, although the weighted between each aspect varies across the articles (See Figure 5). Based on the linked connection, its central theme of research across aspects of the circular economy is visualized. For example, in the environment, we have a social environment and a healthy environment. In economics, researchers look into economic activity, economic growth, and social-environmental economics. Finally, most research investigates social measure, social distancing, science, and economics in the social aspect (See Figure 6).

We use the Latent Dirichlet Allocation (LDA) to categorize 10 important topics from 29 articles based on 10-word tokens. However, due to the similarity of the topics, we have merged them into 6 topics in Figure 7. Before using LDA, we follow the standard steps for computerassisted content analysis (Kirilenko et al.; Heydt; Manning et al.). To ensure the result's reliability and consistency, we run iterations multiple times because, for a burn-in of several 100 iterations, the LDA algorithm will converge towards the maximum of the likelihood function (Schwarz). The function goes beyond the major theme of research papers and tries to find the hidden theme that all of them share.

\begin{tabular}{|l|l|}
\hline Token & Topic Theme Interpretation \\
\hline Covid, Export, Healthcare, Equipment, & Shortage of medical equipment but high medical \\
Wemand, High, Manufacturing, Shortage, & waste during Covid-19 due to the high demand \\
in healthcare.
\end{tabular}




\begin{tabular}{|l|l|}
\hline Pandemic, outbreak, overview, opportunities, & The reports on the impacts of Covid-19 \\
manufacturing, strategies, global, change, & pandemic on the manufacturing globally, and \\
Covid, reported & their coping strategies and new opportunities \\
\hline shipping, aviation, travel, scenario, industry, & The impacts of international restriction on the \\
trade, billion, international, impact, based & tourism, trade, shipping, and aviation industry, \\
& causing billion-dollar losses. \\
\hline air, Covid, reduction, noise, environment, & The reduction of pollution with health \\
China, national, EU, health, pollution & environment improvements. Example with case \\
& study from China and EU \\
\hline
\end{tabular}

Figure 7: Topics extracted from 21 articles where ten tokens most closely associated with the topic are presented.

From the LDA topic analysis in Figure 7, we can see the hidden themes spread across dimensional economic, social, and environmental elements. In these articles, the impacts of Covid19 on the circular economy is both positive and negative. We have conducted close reading analysis about these themes based on Voyant Tools key result suggestions on-trend. An abundance of evidence supports the topic's interpretation. The problems are a shortage of medical devices, economic-social disruption due to lockdown, and economic loss due to the international ban. The positive results are environmental improvement across different pollution types, building the foundation for the circular economy infrastructure. The solutions suggested to cope with Covid19 are opening borders and promoting international trade after Covid-19. 


\section{Discussions on the major topics developed by Latent Dirichlet Allocation}

\section{Shortage of medical equipment but high medical waste during Covid-19 due to the high demand in healthcare.}

Regarding the first topic of Shortage of medical equipment but high medical waste during Covid-19 due to the high demand in healthcare, seven research addresses this topic. Due to the high infection rate of Covid-19, the demand for personal protective equipment rapidly increases due to reliability and affordability. Hence, currently, the United States, India, and the United Kingdom face low supply stock for equipment due to these countries, initially, not promoting stockpiling of essential medical equipment. Moreover, the mass production of ventilation equipment is prevented due to patent rights, asking new producers to design new products to increase the supply of goods. Hence, they are in shortage of ventilation products across different countries (Ibn-Mohammed et al.; Nandi et al.). This lack of protective equipment creates high risks of virus infection for workers in the informal economy (Dewick et al.). Moreover, two research emphasize the environmental consequences of medical waste from one time used for medical protection by doctors and citizens. As the plastic used in medical equipment has low recyclability (Vanapalli et al.) and the public health guideline that reusable medical equipment is unhygienic, the Covid-19 implements plastic dependency and unsustainable plastic usage across the world (Makki et al.). Covid-19 forces humans and the government to make trade-offs between health and the environment, significantly preventing the circular economy. 
However, researchers also find opportunities and solutions to nurture a circular economy amid Covid-19 and medical supply shortage. Firstly, the circular economy's principles provide solutions to the medical equipment shortage issues with repairability, reusability, and remanufacturing. If society and the economy can adopt the circular economy principles, we can create a more resilient and competitive market post the pandemic (Nandi et al.). The practices are sharing, repair, and refurbished medical equipment and devices. Secondly, decentralized and localizing manufacturing involves giving multiple facilities rights across locations within a country to self-producing material. This might not be financially and legally plausible in the current situation; however, it will utilize local materials and reduce global trade dependency. Thirdly, the government can develop an Extended Producer Responsibility scheme to give medical producers an incentive to design environmentally friendly products, such as reusing or recycling (Wuyts et al.). Although the circular economy principles are not short-term solutions for Covid-19, its strategies will solve the long-run problems and prevent other environmental and supply shortage situations in upcoming crises.

\section{The long term negative impacts of lockdown on economic and social activities because of Covid-19 pandemic}

There are 15 pieces of research addressing the negative impacts of lockdown on economic and social activities. Due to the fast spread of Covid-19, lockdown is a measure to prevent citizens from moving freely due to the risk of spreading the virus. During the pandemic, countries worldwide have implemented strict strategies, such as national lockdown and border closures (IbnMohammed et al.; Giudice et al.). The lockdown prevents citizens from work and countries to trade, leading to multiple consequences. According to the IMF, the corona crisis caused a $3 \%$ decrease in the world GDP by April 2020, projected to increase over 6\% post-Covid-19. Moreover, 
the GDP per capita is also predicted to drop in 170 countries (Herstatt and Tiwari). The lockdown is also predicted to cost trillions of dollars in the upcoming years because of the global recession (Ibn-Mohammed et al.). This policy also causes asymmetric shock for both demand and supply. Regarding the supply side, the consequences of medical shortage have been addressed. However, supply issues are not limited to that industry. The food industry, for example, has a significant hit. Millions of people are at the risk of experiencing the disruption of food intake, while the restaurants cannot have customers visit them (Ibn-Mohammed et al.). This is a billion-dollar dilemma that businesses in food and beverage cannot fully solve, despite the increase in demand for delivery services.

Socially, the Covid-19 changes the ways our society functions- in a negative direction. Research has reported that the implementation of a national shutdown renders 130 million employees jobless. Another survey from ActionAid also highlights this issue. Among respondents surveyed until the end of May 2020, 75\% reported losing their livelihood, nearly $50 \%$ had not been paid, around $17 \%$ had gained just partial wages, and over $50 \%$ had owed more debt (Breman). Another emerging diet-related issue is malnourishment. Because the traditional supply chain is restrained, resulting in less available and more expensive fresh fruits and vegetables, an increasing number of people have to resort to highly processed food (Lal et al.). Lost income can make previously affordable meals lavish, inflicting hunger on many millions of people. As unemployment and hunger pave the way for criminal actions and social unrest, the current pandemic is unstabilizing the economy and society. These economic and social challenges pose a threat to sustainable development and limit the incorporation of the circular economy. 


\section{The reports on the impacts of Covid-19 pandemic on the manufacturing globally, and their coping strategies and new opportunities}

13 articles addressed this topic. Impacts of Covid-19 pandemic on the manufacturing globally, and their coping strategies and new opportunities. According to previous research, although the circular economy principles apply to all parts of the economy, its impacts have concentrated on the manufacturing sector. Hence, the manufacturing sector analysis can illuminate researchers on the challenges and opportunities to develop a circular economy amid Covid-19 (Mohan et al.).

The impacts of Covid-19 on manufacturing are enormous across the world. One research indicates that the world-leading manufacturing and export countries, such as Korea, Japan, the UK, German, Italy, and France, are the most hit by the pandemic (Ibn-Mohammed et al.). For example, German is a leading manufacturing country worldwide with total manufacturing values only lesser than Japan, the United States, and the United Kingdoms. During the pandemic, domestic and foreign firms' manufacturing orders have been canceled at a loss of 15\% year-over-year (YOY). The production level of German in total (with price and calendar adjusted) also dropped 11\% on a YOY basis in March 2020 (Herstatt and Tiwari). Moreover, due to the lack of diversification in sourcing strategies, there is a lack of raw materials and highly tech-specialized material for production after the border closedown, causing "manufacturing deserts" across cities, regions, and countries (Ibn-Mohammed et al.).

The circular economy offers several solutions for this global issue. Indicated by 3 pieces of research, localization, agile manufacturing, and implementing recycling-refurbishing techniques can address all the manufacturing difficulties (Nandi et al.; Barcaccia et al.; Neumeyer 
et al.). Firstly, localization in manufacturing processes counters unexpected distance-related risk. Moreover, by localizing purchasing, manufacturing, and $\mathrm{R} \& \mathrm{D}$, the company will gain competitiveness by addressing the local market's demand. The production costs, such as transportation costs and risks related to long traveling and storage, also minimize. A blockchain technology (BCT)-enabled circular economy platform can help firms share leasing to redistribute their new and excess inventory supplies regionally and normalize panic purchases at local grocery stores (Nandi et al.). Agile manufactures are the working principles where processes, tools, and training are prepared to ensure quick responsibility toward customer needs and market changes while still controlling costs and quality. To develop agile manufacturing principles, the business must integrate all sectors of their operation, such as laborers and machines, into lean and flexible components. Finally, by developing recycling and recovery techniques, firms can ensure resources to meet customers' demands even in the pandemic. Moreover, these techniques can reduce production costs; hence, firms can reduce the price to boost demand that has dropped due to Covid19 (Neumeyer et al.). By implementing these practices, firms will be more responsive and better prepared to transform into a circular economy post-Covid-19. In short, although Covid-19 makes huge losses for world manufacturing, it helps firms and countries to appreciate the benefits and develop a more circular economic process across the world.

\section{The impacts of international restriction on the tourism, trade, shipping and aviation industry, causing billion-dollar losses.}

The pandemic impacts on aviation, shipping, tourism, and trade activities are predicted by modeling to cost hundreds of billions of dollars. Firstly, aviation activities face flight cancellations and bans, leading to an immediate loss in aeronautical revenues. Airport, however, still has to maintain and operate with limited avenues to reduce costs. Scenario modeling has been conducted 
with Scenario 1 (Optimistic scenario) and Scenario 2 (Pessimistic scenario). With an optimistic scenario (the Covid-19 would end in May 2020), the Air Transport Bureau estimated an overall reduction of between $39 \%-56 \%$ of airplane seats; $872-1,303$ million passengers. This is equal to the loss of gross operating revenues between 153 billion USD to 231 billion USD. Under the pessimistic scenario (Covid-19 stops at December 2020), the Air Transport Bureau estimated the decline of between $49 \%-72 \%$ of airplane seats, 1,124 to 1,540 million passengers, and between 198 billion USD to 273 billion USD lost in operating revenues. The model is a function of the duration and size of the pandemic and containment measures, economic situations, the pace of economic recovery, and customers' confidence level for air travel (Ibn-Mohammed et al.). It is worth noting that the first scenario has not appeared, and the world may not achieve the end of Covid-19 in 2020. This would mean the loss in the avian industry might go beyond even the pessimistic scenario.

Aviation loss directly impacts tourism, leading the tourism industry also experiences high economic loss. UNWTO reported a drop of $22 \%$ in international tourism. This drop costs $\$ 80$ billion and a loss of 67 million international arrivals in 2020. The modeling also expected a fall between $58 \%$ to $78 \%$ in the arrival of international tourists (Ibn-Mohammed et al.). These trends will hugely impact tourism countries, such as Thailand, Italy, and Spain. For instance, Italy is at risk of losing 12 billion euros in the food and wine tourism sectors (Barcaccia et al.). The restriction of international travel does not only cause economic loss. According to modeling, travel restrictions could cause 100 to 120 million job losses in tourism (Ibn-Mohammed et al.). Trade and shipping industry also faces economic problems. The global volume of merchandise trade also declined by about $13 \%$ in mid-April and a $32 \%$ decline in the subsequent months. In Europe, the shipping industry is experiencing a 'critical' moment where the European community of ship- 
owners' reported that all vessels have significant immediate losses, declining turnover higher than $60 \%$ (Rahman et al.).

Regardless of such loss in the economy, scholars view the pandemic as an opportunity to promote a circular economy in the international supply chain and tourism sectors. Solving climate crises is an integral part of the circular economy. Limiting the increased temperature to below $2^{\circ} \mathrm{C}$ requires rapid and complete decarbonization of energy systems; however, it is traditionally believed to be hard achieved in the aviation and shipping industry. The technological supply-side options alone cannot cut the $\mathrm{CO} 2$ emissions to zero rapidly in aviation and shipping. The significant demand reductions in these two industries to meet the $1.5-2{ }^{\circ} \mathrm{C}$ goal. Hence, the Covid19 pandemic creates a golden opportunity for $\mathrm{CO} 2$ emissions reductions by reallocating from avian transportation to other less energy-intensive transport modes (Sharmina et al.). Still, it should be acknowledged that the impacts of Covid-19 also reduce the available resources for developer recycling facilities, making vessel recycling and developing recycling facilities in the EU, for example, may not be socially, economically, and environmentally sustainable (Rahman et al.).

\section{The reduction of pollution with health and environment improvement. Example with a case study from China and EU}

Despite the many economic, social, and environmental effects, the pandemic has positively transformed citizens' attitudes, behavior, and business operations. These benefits create a growing momentum for transforming customers' consumption, business operations, and production toward the circular economy (Kahlert and Bening; Nandi et al.; Giudice et al.; Herstatt and Tiwari; IbnMohammed et al.; Rubino et al.). The benefits include improvements in air quality, noise quality, and the reduction in $\mathrm{CO} 2$ emission. For example, air quality improvement over the pandemic has 
saved more lives than Covid-19's death in China (Ibn-Mohammed et al.). Covid-19 also reduces problem over-tourism typically related to the displacement of inhabitants, damage to local resources, and a decrease in residents' quality of life (Rubino et al.). Lockdown measures also result in a reduction in the number of road accidents to $23 \%$ in Germany. There is an increase of $12.5 \%$ in the sale of bicycles, sports articles, and camping goods in German also (Herstatt and Tiwari).

However, the discussions mostly revolve around whether these benefits are long-term and, if not, how the government, business, and citizens can keep track of this momentum toward the circular economy. There are various suggestions from scholars, ranging from policymaking to business practice. Policy plays an essential role in the market and national scale, especially financial aid and setting standard industry guidelines. For example, the recycling industry has a low-profit margin; hence, governments' financial aid will motivate firms to increase recycling and be financially ready to develop the latest technology. Vertical and horizontal integration is vital in allowing recyclers to achieve economies of scale (Kahlert and Bening). The recycling industry also needs investment in chemical recycling or automation and digitalization, such as blockchain technology (BCT)-enabled circular economy platform. Scholars investigate localization, agile manufacturing (aforementioned) and frugal innovation, and blockchain technology (BCT)-enabled innovation on a firm scale (Nandi et al.). Frugal innovation simplifies the design and reduces the cost of a good and its production. This type of innovation can shape affordable green excellence in production. If frugal products, services, technologies, and business models can be implemented during the Covid-19 pandemic, it can provide long-term changes in ensuring financial, societal, infrastructural, and ecological sustainability. Blockchain technology (BCT)-enabled innovation by developing decentralized and immutable data, reliable data, transparency, traceability, smart 
contracts, and incentivization. This technology helps solve sustainable supply chain issues, such as food contamination, carbon credits, and scheduled maintenance.

\section{Limitation and suggestion for future research:}

In this section, we concentrate on the systematic review and text-mining key findings, comments on our research method limitation, and provides direction for future research.

Comprehensive but Lack of Empirical Research: Firstly, the research sees the current research trend on the circular economy concentrates on many essential industries in daily life, such as waste management, food and beverage, healthcare, supply chain, and tourism. The research also sees proposals for integrating sustainable practices and smart technology across different economies, such as manufacturing, logistics, and services. However, all these suggestions are perspective-based and theory-based without empirical evidence. There is limited research over the data mining and close-reading process that applies modeling and cost-benefit analysis for their suggestions, making these suggestions vivid in theories but unaccounted for unavailability of resources to implement. This is one of the key literature gaps in the current research trend in the circular economy and Covid-19.

Research concentrates on business and policymakers: Secondly, all researchers acknowledge the opportunities in developing the circular economy practices in Covid-19 pandemics and the necessary global inclusions into the process at a multi-level, such as international organizations, national policymakers, firm owners, and customers. However, the lack of research guides maintaining positive customer behavior post-Covid 19. Most of the suggestions are how to engage firms with customers or policy with citizens, making all suggestions passive from the customers' perspective. Future research in this topic should engage more with customer analysis and develop guidelines to maintain customers' engagement with the circular economy 
during the pandemic and post Covid-19.

Research lacks geographical diversity and economic diversity: Although most of the research touches on the international aspects of Covid-19, their analysis and case studies are revolving around EU nations, such as Poland, Italy, German, Georgia, and Russia. Hence, there is under-representative research from Asian, African, Latin American nations about impacts of Covid-19 on the circular economy. The research for this lack of diversity might because only EU nations actively adopt a circular economy on their national strategies. Moreover, most research on the impacts of Covid-19 on the circular economy concentrates on developed countries. Many advices from this research, such as incorporating blockchain technology in waste recycling or agile manufacturing, might not be affordable by firms in developing countries, especially in the midst of Covid-19. Nevertheless, without inclusion in research from developing countries in the future, it is hard to implement a circular economy across the globe due to the diverse geographical condition, culture, economic situation across the world.

Advantages of Voyant Tools and Data Mining: Finally, we want to comment on the advantages and disadvantages of text-mining in the systematic review, generating visualization, and directing research. Text-mining's key advantages are fast text processing and developing a strong visualization of research corpus with colorful pictures. In this research, the word cloud has illustrated 29 results' concentrating themes and the interdisciplinary of three aspects in the circular economy without the need for close reading and interpretation. This helps researchers to save time and human resources in the research process. Moreover, this technique allows researchers to formulate their hypotheses and follow the research trend easily.

Disadvantages of Voyant Tools and Data Mining: Voyant Tools cannot be used without close reading and domain technical knowledge. This is because the Voyant Tools require authors 
to interpret data without context, which may cause subjectivity and bias in research. There are not also formal guidelines for rigorous and reliable Voyant Tools' and interpretation. For example, the interpretation of 5 major themes does not necessarily reflect the comprehensive nature of all 29 pieces of research on the impacts of Covid-19 on the circular economy. For example, a big section of technology application to promote the circular economy in various research has been excluded from 5 topic generations. Hence, future research should solve these methodology limitations. However, in conclusion, data mining and Voyant Tools should be considered a good supply for systematic review and textual analysis.

\section{Conclusion:}

At the time of this research, Covid-19 has cost the death of 1.6 million citizens and is currently infecting 70 million global citizens. Researchers' simulations and predictions before June 2020 have gone wrong due to the prolongation of the Covid-19, causing economic, social, and environmental loss beyond estimation. Still, under the mist of the pandemic, various technologies, suggestions, and guidelines set out by researchers have been implemented around the world and publicly cited by international organizations, such as the World Economic Forum (WEF), WHO, and Food Agriculture Organization (OECD). For example, the Organisation for Economic Cooperation and Development (OECD) calls for the localization of production (Yueh), and WEF promotes blockchain technology to track Covid-19 vaccine supply (Korin). These results should be credited to the research community and their contribution to the circular economy in the pandemic situation.

The circular economic perspective is undoubtedly the negative consequences and pressures from the pandemic on all three aspects of the circular economy. The problems are not limited to the health and environmental trade-off from one-time-use plastics, the economy and health trade- 
off from lockdown or economy and social trade-off from million job loss and business shutdown. With in-depth research and guidelines set out by researchers, there might be a light from the darkness. Policymakers, businesses, and customers are seeing direct and indirect benefits from the circular economy's principles and practices. By nurturing the circular economy practices during the pandemic, we will develop a more sustainable and resilient world in the future regardless of another pandemic like Covid-19.

For suggestions on future research, we suggest more empirical research and cost-benefit analysis of the circular economy strategies on combating Covid-19. Researchers should also work on analyzing the opportunities and challenges to promote a circular economy from customers' and citizen perspectives during and after the pandemic. Finally, researchers should also concentrate on developing countries and regional areas beyond Europe. Following these suggestions, research, as a whole, will become more data-driven, practical, and inclusive for policymakers, businesses, and citizens across the world.

\section{Funding source}

No source was secured.

\section{Declaration of Competing Interest}

The authors of this article declare that they have no conflict of interests.

\section{Acknowledgments}

\section{References:}

Abel GJ, Gietel-Basten S. 2020. International remittance flows and the economic and social consequences of COVID-19. Environment and Planning A: Economy and Space 52:1480- 


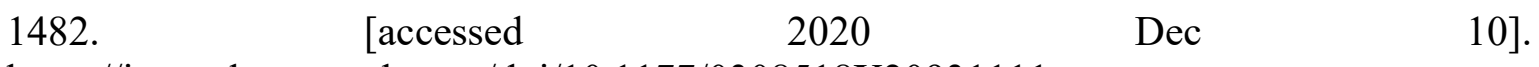
https://journals.sagepub.com/doi/10.1177/0308518X20931111

Agardy FJ, Nemerow NL, editors. 2005. Environmental solutions. Amsterdam: Elsevier. [accessed 2020 Dec 10]. https://doi.org/10.1016/B978-0-12-088441-4.X5000-X

Atani M. 2020. Promoting African green business and circular economy for better policies. UN Environment. [accessed 2020 Dec 10]. https://www.unenvironment.org/news-andstories/story/promoting-african-green-business-and-circular-economy-better-policies

Ateljevic I. 2020. Transforming the (tourism) world for good and (re)generating the potential 'new normal.' Tourism Geographies 22:467-475. [accessed 2020 Dec 10]. https://doi.org/10.1080/14616688.2020.1759134

Barcaccia G, D'Agostino V, Zotti A, Cozzi B. 2020. Impact of the SARS-CoV-2 on the Italian Agri-Food Sector: An Analysis of the Quarter of Pandemic Lockdown and Clues for a SocioEconomic and Territorial Restart. Sustainability 12:5651. [accessed 2020 Dec 10]. https://doi.org/10.3390/su12145651

Bassens D, Kębłowski W, Lambert D. 2020. Placing cities in the circular economy: neoliberal urbanism or spaces of socio-ecological transition? Urban Geography 41:893-897. [accessed 2020 Dec 10]. https://doi.org/10.1080/02723638.2020.1788312

Breman J. 2020. The Pandemic in India and Its Impact on Footloose Labour. The Indian Journal of Labour Economics. [accessed 2020 Dec 10]. 10.1007/s41027-020-00285-8

Chadegani AA, Salehi H, Yunus MM, Farhadi H, Fooladi M, Farhadi M, Ebrahim NA. 2013. A Comparison between Two Main Academic Literature Collections: Web of Science and Scopus Databases. Asian Social Science 9. [accessed 2020 Dec 10]. https://doi.org/10.5539/ass.v9n5p18

Chauhan A, Jakhar SK, Chauhan C. 2021. The interplay of circular economy with industry 4.0 enabled smart city drivers of healthcare waste disposal. Journal of Cleaner Production 279:123854. [accessed 2020 Dec 10]. https://doi.org/10.1016/j.jclepro.2020.123854

Chen C-W. 2018. Guidance on the Conceptual Design of Sustainable Product-Service Systems. Sustainability 10:2452. [accessed 2020 Dec 10]. https://doi.org/10.3390/su10072452

Circular economy and health: opportunities and risks. 0AD. Copenhagen: WHO Regional Office for Europe.

The Circular Economy In Detail. 2020. Ellen MacArthur Foundation. [accessed 2020 Dec 9]. https://www.ellenmacarthurfoundation.org/explore/the-circular-economy-in-detail

Circular economy: definition, importance and benefits: News: European Parliament. 2018 Apr 10. Circular economy: definition, importance and benefits | News | European Parliament. 
[accessed

2020

Dec

9].

https://www.europarl.europa.eu/news/en/headlines/economy/20151201STO05603/circulareconomy-definition-importance-and-benefits

Dewick P, Pineda J, Ramlogan R. 2020. Hand in Glove? Processes of Formalization and the Circular Economy Post-COVID-19. IEEE Engineering Management Review 48:176-183. [accessed 2020 Dec 10]. DOI:10.1109/EMR.2020.3014014

Enkvist P-A, Klevnäs P. 2018. Material Economics. [accessed 2020 Dec 10]. https://materialeconomics.com/publications/the-circular-economy-a-powerful-force-forclimate-mitigation-1

Fritschi L, editor. 2011. Burden of disease from environmental noise: quantification of healthy life years lost in Europe. Copenhagen, Denmark: World Health Organization, Regional Office for Europe.

Gao W. 2017. Text Analysis of Communication Faculty Publications to Identify Research Trends and Interest. Behavioral \& Social Sciences Librarian 36:36-47. [accessed 2020 Dec 10]. https://doi.org/10.1080/01639269.2017.1507223

Giudice F, Caferra R, Morone P. 2020. COVID-19, the Food System and the Circular Economy: Challenges and Opportunities. Sustainability 12:7939. [accessed 2020 Dec 10]. https://doi.org/10.3390/su12197939

Haggar SE. 2010. Chapter 3 - Sustainable Development and Industrial Ecology. In: Sustainable Industrial Design and Waste Management: Cradle-to-Cradle for Sustainable Development. Burlington: Elsevier Science. p. 85-124. [accessed 2020 Dec 10]. https://doi.org/10.1016/B978-012373623-9/50005-8

Han J, Kamber M, Pei J. 2012. Data Mining Trends and Research Frontiers. Data Mining:585631. [accessed 2020 Dec 10]. https://doi.org/10.1016/B978-0-12-381479-1.00013-7

Herstatt C, Tiwari R. 2020. Opportunities of frugality in the post-corona era. International Journal of Technology Management 83:15. [accessed 2020 Dec 10]. 10.1504/IJTM.2020.109276

Hetenyi G, Lengyel AD, Szilasi MD. 2019. Quantitative analysis of qualitative data: Using voyant tools to investigate the sales-marketing interface. Journal of Industrial Engineering and Management 12:393. [accessed 2020 Dec 10]. http://dx.doi.org/10.3926/jiem.2929

Heydt M. 2018. Python web scraping cookbook: over 90 proven recipes to get you scraping with Python, microservices, Docker, and AWS. Birmingham, UK: Packt Publishing. [accessed 2020 Dec 10]. https://www.amazon.com/Python-Web-Scraping-Cookbook-microservicesebook/dp/B077NC4TQP 
Ibitz A. 2020. The Implications of Brexit for Establishing a European Circular Economy. Tamkang Journal of International Affairs 7. [accessed 2020 Dec 10]. https://doi.org/10.6185/TJIA.V.202007_24(1).0001

Ibn-Mohammed T, Mustapha K, Godsell J, Adamu Z, Babatunde K, Akintade D, Acquaye A, Fujii $\mathrm{H}$, Ndiaye M, Yamoah F, et al. 2021. A critical analysis of the impacts of COVID-19 on the global economy and ecosystems and opportunities for circular economy strategies. Resources, Conservation and Recycling 164:105169. [accessed 2020]. https://doi.org/10.1016/j.resconrec.2020.105169

International Tourism Down $70 \%$ as Travel Restrictions Impact All Regions. 2020. WORLD TOURISM ORGANIZATION (UNWTO). [accessed 2020 Dec 10]. https://www.unwto.org/taxonomy/term/347

Kahlert S, Bening CR. 2020. Plastics recycling after the global pandemic: resurgence or regression? Resources, Conservation and Recycling 160:104948. [accessed 2020 Dec 10]. DOI:10.1016/j.resconrec.2020.104948

Kalmykova Y, Sadagopan M, Rosado L. 2018. Circular economy - From review of theories and practices to development of implementation tools. Resources, Conservation and Recycling 135:190-201. [accessed 2020 Dec 10]. https://doi.org/10.1016/j.resconrec.2017.10.034

Kirilenko AP, Stepchenkova SO, Dai X. 2021. Automated topic modeling of tourist reviews: Does the Anna Karenina principle apply? Tourism Management 83:104241. [accessed 2020 Dec 10]. https://doi.org/10.1016/j.tourman.2020.104241

Korhonen J, Granberg B. 2020. Sweden Backcasting, Now? —Strategic Planning for Covid-19 Mitigation in a Liberal Democracy. Sustainability 12:4138. [accessed 2020]. https://doi.org/10.3390/su12104138

Korin N. 2020 Nov 20. Using blockchain to monitor the COVID-19 vaccine supply chain. World Economic Forum. [accessed 2020 Dec 10$]$. https://www.weforum.org/agenda/2020/11/using-blockchain-to-monitor-covid-19-vaccinesupply-chain/

Lal R, Brevik EC, Dawson L, Field D, Glaser B, Hartemink AE, Hatano R, Lascelles B, Monger C, Scholten T, et al. 2020. Managing Soils for Recovering from the COVID-19 Pandemic. Soil Systems 4:46. [accessed 2020 Dec 10]. https://doi.org/10.3390/soilsystems 4030046

Linder M, Williander M. 2015. Circular Business Model Innovation: Inherent Uncertainties. Business Strategy and the Environment 26:182-196. [accessed 2020 Dec 10]. https://doi.org/10.1002/bse.1906

Mahler DG, Lakner C, Aguilar RAC, Wu H. 2020. The impact of COVID-19 (Coronavirus) on global poverty: Why Sub-Saharan Africa might be the region hardest hit. World Bank Blogs. 
[accessed 2020 Dec 10]. https://blogs.worldbank.org/opendata/impact-covid-19coronavirus-global-poverty-why-sub-saharan-africa-might-be-region-hardest

Makki F, Lamb A, Moukaddem R. 2020. Plastics and the coronavirus pandemic: a behavioral science perspective. Mind \& Society. [accessed 2020 Dec 10]. https://doi.org/10.1007/s11299-020-00258-w

Manning CD, Raghavan P, Schütze H. 2018. Introduction to information retrieval. Cambridge: Cambridge University Press. [accessed 2020 Dec 10]. https://nlp.stanford.edu/IRbook/information-retrieval-book.html

Marwick B. 2014. Discovery of Emergent Issues and Controversies in Anthropology Using Text Mining, Topic Modeling, and Social Network Analysis of Microblog Content. Data Mining Applications with R:63-93. [accessed 2020 Dec 10]. https://doi.org/10.1016/B978-0-12411511-8.00003-7

Mohan SV, Hemalatha M, Amulya K, Velvizhi G, Chiranjeevi P, Sarkar O, Kumar AN, Krishna KV, Modestra JA, Dahiya S, et al. 2020. Decentralized Urban Farming Through Keyhole Garden: a Case Study with Circular Economy and Regenerative Perspective. Materials Circular Economy 2. [accessed 2020]. https://doi.org/10.1007/s42824-020-00011-1

Moher D, Liberati A, Tetzlaff J, Altman DG. 2009. Preferred Reporting Items for Systematic Reviews and Meta-Analyses: The PRISMA Statement. PLoS Medicine 6. [accessed 2020 Dec 10]. https://doi.org/10.1371/journal.pmed.1000097

Morgan J, Mitchell P. 2015. Employment and the circular economy: job creation in a more resource efficient Britain. London: Green Alliance.

Muhammad S, Long X, Salman M. 2020. COVID-19 pandemic and environmental pollution: A blessing in disguise? Science of The Total Environment 728:138820. [accessed 2020]. https://doi.org/10.1016/j.scitotenv.2020.138820

Murray A, Skene K, Haynes K. 2015. The Circular Economy: An Interdisciplinary Exploration of the Concept and Application in a Global Context. Journal of Business Ethics 140:369-380. [accessed 2020 Dec 10]. https://doi.org/10.1007/s10551-015-2693-2

Nandi S, Sarkis J, Hervani AA, Helms MM. 2021. Redesigning Supply Chains using BlockchainEnabled Circular Economy and COVID-19 Experiences. Sustainable Production and Consumption 27:10-22. [accessed 2020 Dec 10]. https://doi.org/10.1016/j.spc.2020.10.019

Neave L. 2020. What constitutes discovery? An analysis of published interviews with fiction writers and biomedical scientists. New Writing:1-13. [accessed 2020 Dec 10]. https://doi.org/10.1080/14790726.2020.1760307 
Nechifor V, Calzadilla A, Bleischwitz R, Winning M, Tian X, Usubiaga A. 2020. Steel in a circular economy: Global implications of a green shift in China. ScienceDirect. [accessed 2020 Dec 9]. https://doi.org/10.1016/j.worlddev.2019.104775

Nettleton D. 2014. Chapter 11 - Text Analysis. In: Commercial Data Mining Processing, Analysis and Modeling for Predictive Analytics Projects. Amsterdam: Elsevier. p. 171-179. [accessed 2020]. https://doi.org/10.1016/B978-0-12-416602-8.00011-X

Neumeyer X, Ashton WS, Dentchev N. 2020. Addressing resource and waste management challenges imposed by COVID-19: An entrepreneurship perspective. Resources, Conservation and Recycling 162:105058. [accessed 2020 Dec 10]. https://doi.org/10.1016/j.resconrec.2020.105058

Nukhu R, Singh S. 2020. Branding dilemma: the case of branding Hyderabad city. International Journal of Tourism Cities 6:545-564. [accessed 2020 Dec 10]. https://doi.org/10.1108/IJTC08-2019-0130

Padilla-Rivera A, Russo-Garrido S, Merveille N. 2020. Addressing the Social Aspects of a Circular Economy: A Systematic Literature Review. Sustainability 12:7912. [accessed 2020 Dec 10]. https://doi.org/10.3390/su12197912

Patel N. 2020. Impact on Dental Economics and Dental Healthcare Utilization in COVID-19: An Exploratory Study. Journal of Advanced Oral Research 11:128-136. [accessed 2020 Dec 10]. 10.1177/2320206820941365

Pavliashvili S, Prasek DE. 2020. Accelerating Transition to the Circular Economy in Georgia. Bulletin of the Georgian National Academy of Sciences 14. [accessed 2020 Dec 10]. http://science.org.ge/bnas/t14-n3/01_Pavliashvili_Inaugural\%20Article.pdf

Peng Y, Zhang Z, Wang X, Yang L, Lu L. 2020. Text mining and deep learning for disease classification. Handbook of Medical Image Computing and Computer Assisted Intervention:109-135. [accessed 2020 Dec 10]. https://doi.org/10.1016/B978-0-12-816176$0.00010-7$

Pieroni MP, Mcaloone TC, Pigosso DC. 2019. Business model innovation for circular economy and sustainability: A review of approaches. Journal of Cleaner Production 215:198-216. [accessed 2020 Dec 10]. https://doi.org/10.1016/j.jclepro.2019.01.036

Preston F, Lehne J, Wellesley L, Sugathan M. An Inclusive Circular Economy: Priorities for Developing Countries. Chatham House. [accessed 2020 Dec 10]. https://www.chathamhouse.org/sites/default/files/publications/research/2019-05-22Circular\%20Economy.pdf

Prideaux B, Thompson M, Pabel A. 2020. Lessons from COVID-19 can prepare global tourism for the economic transformation needed to combat climate change. Tourism Geographies 22:667-678. [accessed 2020 Dec 10]. https://doi.org/10.1080/14616688.2020.1762117 
Quéré CL, Jackson RB, Jones MW, Smith AJP, Abernethy S, Andrew RM, De-Gol AJ, Willis DR, Shan Y, Canadell JG, et al. 2020. Temporary reduction in daily global CO2 emissions during the COVID-19 forced confinement. Nature Climate Change 10:647-653. [accessed 2020]. $10.1038 / \mathrm{s} 41558-020-0797-\mathrm{x}$

Rada EC, Magaril ER, Schiavon M, Karaeva A, Chashchin M, Torretta V. 2020. MSW Management in Universities: Sharing Best Practices. Sustainability 12:5084. [accessed 2020 Dec 10]. https://doi.org/10.3390/su12125084

Rahman SM, Kim J, Laratte B. 2021. Disruption in Circularity? Impact analysis of COVID-19 on ship recycling using Weibull tonnage estimation and scenario analysis method. Resources, Conservation and Recycling 164:105139. [accessed 2020 Dec 10]. https://doi.org/10.1016/j.resconrec.2020.105139

Reilly AH. 2020. Social Media, Sustainability and Organizations. Encyclopedia of the World's Biomes:397-406. [accessed 2020 Dec 10]. https://doi.org/10.1016/B978-0-12-4095489.11972-4

Rizos V, Tuokko K, Behrens A. Circular economy A review of definitions, processes and impacts. Ecologic Institute. $\quad$ [accessed $2020 \quad$ Dec 10$]$. https://www.ecologic.eu/sites/files/publication/2017/2809-circular-impacts_0.pdf

Rubino I, Coscia C, Curto R. 2020. Identifying Spatial Relationships between Built Heritage Resources and Short-Term Rentals before the Covid-19 Pandemic: Exploratory Perspectives on Sustainability Issues. Sustainability 12:4533. [accessed 2020]. https://doi.org/10.3390/su12114533

Schwarz C. 2018. Ldagibbs: A Command for Topic Modeling in Stata Using Latent Dirichlet Allocation. The Stata Journal: Promoting communications on statistics and Stata 18:101117. [accessed 2020 Dec 10]. https://doi.org/10.1177/1536867X1801800107

Schwarz C. 2018. Ldagibbs: A Command for Topic Modeling in Stata Using Latent Dirichlet Allocation. The Stata Journal: Promoting communications on statistics and Stata 18:101117. [accessed 2020 Dec 10]. https://doi.org/10.1177/1536867X1801800107

Sehnem S, Vazquez-Brust D, Pereira SCF, Campos LM. 2019. Circular economy: benefits, impacts and overlapping. Supply Chain Management: An International Journal 24:784-804. [accessed 2020 Dec 10]. https://doi.org/10.1108/SCM-06-2018-0213

Sharmina M, Edelenbosch OY, Wilson C, Freeman R, Gernaat DEHJ, Gilbert P, Larkin A, Littleton EW, Traut M, Vuuren DPV, et al. 2020. Decarbonising the critical sectors of aviation, shipping, road freight and industry to limit warming to $1.5-2^{\circ} \mathrm{C}$. Climate Policy: $1-$ 20. [accessed 2020 Dec 10]. 10.1080/14693062.2020.1831430

Singh V, Asari VK, Kumar S, Patel RB, Papneja S, Sharma K, Khilwani N. 2021. Content Recommendation Based on Topic Modeling. In: Computational methods and data 
engineering proceedings of ICMDE 2020. Singapore: Springer. p. 1-10. [accessed 2020]. https://doi.org/10.1007/978-981-15-6876-3_1

Smits M-J, Woltjer G. 2018. [accessed 2020 Dec 10]. https://circular-impacts.eu/library/1772

Talabis MRM, McPherson R, Miyamoto I, Martin JL. 2015. Chapter 1 - Analytics Defined. In: Information security analytics: finding security insights, patterns, and anomalies in big data. Waltham, MA: Syngress. p. 1-12. [accessed 2020 Dec 10]. https://doi.org/10.1016/B978-012-800207-0.00001-0

Trade shows signs of rebound from COVID-19, recovery still uncertain. 2020. World Trade

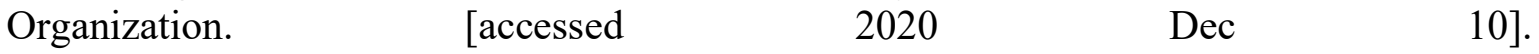
https://www.wto.org/english/news_e/pres20_e/pr862_e.htm

Vanapalli KR, Sharma HB, Ranjan VP, Samal B, Bhattacharya J, Dubey BK, Goel S. 2021. Challenges and strategies for effective plastic waste management during and post COVID19 pandemic. Science of The Total Environment 750:141514. [accessed 2020 Dec 10]. https://doi.org/10.1016/j.scitotenv.2020.141514

Varbanov PS, Jia X, Lim JS. 2020. Process assessment, integration and optimisation: The path towards cleaner production. Journal of Cleaner Production:124602. [accessed 2020 Dec 10]. https://doi.org/10.1016/j.jclepro.2020.124602

World Economic Outlook, October 2020: A Long and Difficult Ascent. 2020. Washington: International Monetary Fund.

Wuyts W, Marin J, Brusselaers J, Vrancken K. 2020. Circular economy as a COVID-19 cure? Resources, Conservation and Recycling 162:105016. [accessed 2020 Dec 10]. $10.1016 /$ j.resconrec.2020.105016

Yueh L. 2020 Nov 12. Localisation of production: COVID-19's medium-term impact. Development Matters. [accessed 2020 Dec 10]. https://oecd-developmentmatters.org/2020/04/27/localisation-of-production-covid-19s-medium-term-impact/

Zaleski P, Chawla Y. 2020. Circular Economy in Poland: Profitability Analysis for Two Methods of Waste Processing in Small Municipalities. Energies 13:5166. [accessed 2020 Dec 10]. https://doi.org/10.3390/en13195166

Zhou Z, Zhou X, Qian L. 2021. Online Public Opinion Analysis on Infrastructure Megaprojects: Toward an Analytical Framework. Journal of Management in Engineering 37:04020105. [accessed 2020 Dec 10]. https://doi.org/10.1061/(ASCE)ME.1943-5479.0000874 